\title{
Introduction to the Special Issue on Queer/ing Criminology: New Directions and Frameworks
}

\author{
Matthew Ball • Carrie L. Buist • Jordan Blair Woods
}

Published online: 24 December 2013

(C) Springer Science+Business Media Dordrecht 2013

Over twenty years ago, sexuality studies and queer theory arrived on the academic and political scenes of the global North and asserted themselves as forces to be reckoned with. It has been almost as long since criminologists made initial calls for criminology to confront these new challenges. Yet, to date, the response to these calls within criminology has been limited at best. While a body of research that considers the criminal justice experiences of queer communities is slowly growing, the field still lacks a sense of itself and what it might be. The recent publication of Dana Petersen and Vanessa R. Panfil's monumental Handbook of LGBT Communities, Crime, and Justice (2014) is a sign that things are slowly changing. Nevertheless, there has yet to be a sustained conversation about the theoretical development of "queer criminology."

This special issue seeks to address this oversight by exploring how critical criminologies might be able to assist in increasing criminological engagement with lesbian, gay, bisexual, transgender, and queer (LGBTQ) communities, and the panoply of concepts utilized when exploring sexual orientation and gender identity. Critical criminologies hold out a lot of hope for those seeking to address the social and criminal injustices experienced by marginalized communities, including LGBTQ communities. Thus, critical criminology seems to be a natural starting point for queer/ing criminology, even if, as some of the authors here would suggest, existing conceptual frameworks within this broad umbrella might need to be updated, or new ones developed.

\footnotetext{
M. Ball

School of Justice, Queensland University of Technology, GPO Box 2434, Brisbane 4001, Australia e-mail: mj.ball@qut.edu.au

M. Ball

Centre for Sex, Gender and Sexualities, Durham University, Durham, UK

C. L. Buist

Department of Sociology and Criminology, University of North Carolina Wilmington, 601 South College Road, Wilmington, NC 28403, USA

J. B. Woods ( ()

UCLA School of Law, 405 Hilgard Ave., Box 951476, Los Angeles, CA 90095, USA
} 
So, what is queer criminology? While some of the following articles flesh this out in more detail than others, we would like to offer our own initial reflections on what it might mean. Queer criminology is a diverse array of criminology-related researches, critiques, methodologies, perspectives, and reflections. These projects might engage in some way with the slippery notion of "queer," focus on how people experience or perform sexuality and gender (with particular attention to those whose lives fall outside of what is considered to be "normative"), or challenge other normative orderings and the criminological methods that support and perpetuate them. These studies might also include empirical projects that chart the experiences of queer populations within criminal justice institutions. Most often, these studies would lead to critiques of mainstream criminology, further theoretical reflection, and political projects that seek to address injustice and inequality. Granted, this is a very expansive definition, and open to further refinement. But it is one that is appropriate in the present context, and canvasses the diverse contributions that are assembled in this special issue.

This special issue opens with two contributions that ask direct questions about the connections between critical criminology and queer criminology, and articulate two possible directions for future queer criminological scholarship. The first, by Jordan Blair Woods, provides a systematic critique of the way in which early and more recent critical criminologies have engaged with LGBTQ people and related concepts, pointing out the significant oversights in these bodies of work. Building on this critique, Matthew Ball points out that despite the significant connections between critical criminology and queer criminology, these connections are not necessarily to be taken for granted, due to the many different ways in which the term "queer" can be used. Both Woods and Ball then chart new directions for queer criminology in order to address these oversights, and craft specific approaches that adequately account for queers in the context of these disciplines. Woods suggests a "queer realism" that treads a path between identity-based perspectives and deconstructive approaches, while Ball suggests a queer criminology that takes queer as a position informed by a notion of critique as the "art of not being governed." The contribution by Carrie L. Buist and Codie Stone, which follows these opening articles, demonstrates the clear need for queer criminological analyses. Buist and Stone recount the experiences of transgender victims and offenders in the criminal justice system in the United States, highlighting its numerous failures and the points at which injustice is perpetuated, particularly through the policing of gender binaries. It serves as a stark reminder that the concerns of transgender communities are central to queer criminology, and that queer struggles for justice are incomplete if transgender communities continue to have the experiences that Buist and Stone report.

The next four contributions offer detailed queer analyses of key issues facing specific communities or groups. In so doing, they enrich the debates within their specific fields of criminology, and continue the necessary empirical task of charting the interactions that queer communities have with the justice system. Building on Buist and Stone's article, Barbara Perry and D. Ryan Dyck's contribution offers an insight into hate crime as experienced by transgender women in Canada. They point out the ways in which hate crimes are used to maintain gender norms, resulting in what the authors term "hyper vigilance" on the part of trans women, who live constantly under the threat of violence and must police their own behavior as a result. This situation is only compounded-and indeed normalized-by the absence of an effective language through which these experiences might be articulated and validated. Continuing with the theme of personal safety, Bianca Fileborn's contribution explores LGBTQ young people in Australia and their experiences of personal safety and unwanted sexual attention, particularly in entertainment venues. 
Fileborn charts the connections between violence, identity, and space, pointing out the ways in which supposedly "safe" spaces can in fact be "unsafe." Angela Dwyer's contribution also considers the experiences of LGBTQ young people in Australia, but with a focus on the experiences that they have with police. Dwyer is particularly interested in the complex ways that the notion of "risk" plays out in the policing of this group, highlighting the complex ways that risk is embodied by LGBTQ young people, making them visible in particular ways, and ultimately demonstrating that particular kinds of queer visibility can have differential impacts on the ways in which they are policed. While the contributions of Fileborn and Dwyer do not only focus on the victimization of members of queer communities, but also their offending behavior, Vanessa R. Panfil's contribution explicitly focuses on their offending. In particular, through ethnographic and participatory research, Panfil brings to light the experiences of gay male gang members in the United States, and the ways in which they negotiate masculinity, sexuality, and their participation in violence. Panfil also offers some important reflections about the dangers of undertaking research into queer offending, and whether such research might in fact work against the broader goals of achieving better justice for queer communities.

Panfil's closing reflections on what kinds of research ought to be undertaken by queer criminologists returns us, in the final three contributions to this special issue, to the theoretical and empirical development of queer criminology. These articles critique the theoretical approaches, empirical objects, or assumptions of criminological work in their respective areas, and balance the broad conceptual and theoretical articles that open this issue with more detailed analyses. Doug Meyer's contribution offers a critique of hate crime laws that is attuned to the way in which they simultaneously protect some people from violence while also expanding the modes of social control that reproduce and intensify inequalities. Against the backdrop of the United States and its extraordinarily high incarceration rates, Meyer's article forces us to reconsider the implementation and expansion of hate crime legislation as a tool for achieving protection and justice for queer communities, especially if it reinforces the very source of injustice for others. Extending this kind of queer critique of the state, Cara Gledhill highlights the ways in which the state enforces the hegemony of heterosexuality and binary conceptions of gender. In the tradition of many other critical criminologies, Gledhill asks us to consider whether it might be useful to consider the state's role here as a form of state crime, and thereby hold the state responsible for the forms of violence, injustice, and exclusion (not to mention the various rights abuses) produced by its institutionalization of heterosexuality and gender binaries. The concluding article in this special issue turns the attention of queer criminologists towards a specific school of critical criminological thought—cultural criminology. Brian Jay Frederick's contribution suggests that explanations for transgressive behavior as proposed within cultural criminology, which see transgression as a product of the social exclusion of particular groups, cannot adequately account for different forms of transgression among gay men, because of the increasing inclusion of gay men within social institutions across the West. Instead, Frederick suggests that we might better understand these kinds of transgressive behavior as a response to new forms of homonormativity among gay men. This, along with each of the previous contributions to this special issue, is a clear example of the ways in which we must expand or reformulate the common assumptions within criminological schools of thought if criminology is to most effectively speak to queer communities and concerns.

While the articles in this special issue illustrate the diversity of intellectual endeavors that might constitute queer criminology, they do not exhaust all of its possibilities, or all of the questions that ought to be asked of it. One important limitation of these contributions is 
the lack of discussions outside of the "global North," and issues of relevance to Indigenous peoples within the "global North." While there is an international flavor to these contributions-including work from Australia, the United Kingdom, the United States, and Canada-and many of these works recognize the importance of intersectional understandings of race, nationality, gender, class, and sexuality among others-these discussions primarily focus on "Northern" concerns and contexts (much like a lot of queer theorizing in other disciplines, we might add). Therefore, we view this special issue as a beginning point and underscore the necessity that future work in queer criminology confronts this limitation, and, opens itself up to critical reflections that chart the connections or tensions between, for example, queer/ed criminologies and counter-colonial criminologies.

If nothing else, this critique suggests that the project of queer/ing criminology is always unfinished and must remain an open space in which such diversity of perspectives, methods, critiques, and reflections can flourish. Queer criminology can speak to a number of people and communities. It can take us down multiple paths, and it can remain an open space of intellectual and political contestation. And, like all critical criminologies, it can, and indeed should, remain engaged in a constant struggle to achieve justice, eliminate inequality, and challenge subordination.

The guest editors thank David Kauzlarich and the rest of the journal's editorial board for supporting this special issue. 